\title{
An analysis of metaphorical idioms in South African Indian English*
}

\author{
Suren Naicker \\ Department of Linguistics and Modern Languages, University of South Africa \\ E-mail: naicks@unisa.ac.za
}

\begin{abstract}
This study looks at a selected number of expressions used in the variety of English known as "South African Indian English" (SAIE). Mesthrie (1992, 2010a) compiled a dictionary of expressions used within this language variety, which is the primary source of data for this study. Mesthrie has also published numerous scholarly works documenting various aspects of SAIE (cf. Mesthrie 1991, 1992a). A selection of five metaphorical idioms have been chosen for analysis, and the meanings as put forth by Mesthrie (1992, 2010a) have been cross-checked with 10 native speakers of SAIE, as well as the author's native-speaker intuitions. The informants were all middle-class, professional, educated persons of Indian origin, who speak English as a first language; they were all between 30 and 60 years of age, and reside either in Johannesburg as internal economic migrants from Durban, or currently reside in Durban. As this analysis is undertaken through the lens of Conceptual Metaphor Theory, the various metaphorical idioms are analysed as expressions of underlying conceptual metaphors, which confirms the idea that many entrenched idiomatic expressions are surface manifestations of underlying conceptual metaphors, and therefore part and parcel of the same human conceptual system. The analysis follows an adapted format used by Kövecses (2010), whereby the metaphorical idiom is stated, followed by the meaning, then the underlying conceptual metaphor. A table illustrating how the idiom is typically mapped in context, followed by a brief discussion of the import, is also in line with Kövecses (2010). One of the key findings is that this is indeed a viable approach to the study of idioms in general, and a more comprehensive study should be made of more expressions like these to see whether or not all entrenched expressions can be viewed as emanating from underlying conceptual metaphors.
\end{abstract}

Keywords: South African Indian English; Conceptual Metaphor Theory; Cognitive Linguistics; metaphorical idioms

\footnotetext{
${ }^{*}$ The author would like to thank his colleague, Maxine Schaefer, for her valuable insights on an earlier draft of this paper.
} 


\section{Introduction}

This study aims to look at a fairly marginalised variety of English spoken in South Africa, commonly known as "South African Indian English". Following Trudgill (1999), the term "variety" will be used instead of "dialect", since the latter may have a negative connotation for some. This variety of English is spoken by the approximately 1.3 million South African Indians residing in South Africa, who are descendants of the indentured labourers who were brought to the country by the British between 1860 and 1911 (Desai and Vahed 2010). Given South Africa's unique history of racial segregation, South African Indians lived separately from other race groups, and therefore developed a variety of English over time which is uniquely South African. Often, linguistic and cultural stereotypes are parodied on South African "Indian" radio stations like Lotus FM, and there have been various "indi" movies made about this group as well. An example of the latter is White Gold ${ }^{1}$ (2005), which tells the story of the arrival of the first group of Indians in South Africa on 16 November 1860. Satirical comedies like Run for your Life ${ }^{2}$ (2002), Broken Promises ${ }^{3}$ (2001), and Keeping up with the Kandasamys ${ }^{4}$ (2016) also constitute sources of these linguistic and cultural parodies. Mesthrie has written fairly extensively on SAIE from various perspectives, including an analysis within the context of language shift (Mesthrie 1992a), and the compilation of two dictionaries documenting terms/phrases used in SAIE (Mesthrie 1992b, 2010a).

Theoretically, this study looks specifically at five salient idioms used in SAIE from a Cognitive Linguistic perspective, using Conceptual Metaphor Theory (CMT) as a framework. The crux of the argument here is that idioms are not analogous to lexemes, which need to be learnt by rote because they are arbitrary words with contingent etymologies. The idioms analysed here should be seen as entrenched linguistic metaphors, which are manifestations of underlying conceptual metaphors that are well-known and well expounded upon in the literature. Hence, the idioms are not as quirky and idiosyncratic as many assume, which begs the question as to why versions of "standard" English are frowned upon in the first place.

\section{Theoretical framework}

The theoretical framework used here falls within the domain of Cognitive Linguistics, and more specifically within a branch of the enterprise known as Cognitive Semantics. The specific theory is known as Conceptual Metaphor Theory (CMT), and is premised on the idea that many metaphors that are used in everyday speech are in fact surface manifestations of underlying conceptual metaphors. Lakoff and Johnson (1980) were the first to popularise this idea, which can be illustrated with the well-known LOVE IS A JOURNEY ${ }^{5}$ metaphor. What they found was that there are several metaphorical expressions about love pertaining to the domain JOURNEY, yet these metaphorical expressions were never really explicitly seen as being related until Lakoff and Johnson pointed out that LOVE is such an abstract concept that it needs to be construed in concrete terms, and the domain of JOURNEY is often used for this purpose (Lakoff and Johnson 1980: 110). For example, the phrases off the tracks, on the rocks, and not going anywhere, though ostensibly saying different things, can all be seen as surface manifestations of the LOVE IS A JOURNEY

\footnotetext{
${ }^{1}$ Moodley, J. (director). White Gold. Durban: African Lotus Productions.

${ }^{2}$ Naidu, K. (director). Run for your life. Johannesburg: Garuda Motion Pictures.

${ }^{3}$ Naidu, K. (director). Broken Promises. Johannesburg/Durban: Garuda Motion Pictures.

${ }^{4}$ Moodley, J. (director). Keeping up with the Kandasamys. Durban: African Lotus Productions.

${ }^{5}$ As is the norm in Cognitive Semantics, hypothetical conceptual domains are written in SMALL CAPS.
} 
metaphor where the lovers are travellers, and the progress of their relationship is seen as progress on a journey taking place on a road, etc. Once a consistent source domain has been identified, the metaphor can be extended in various ways by adding elements from the relevant frame and manipulating it in various ways, as is the case with many jokes and novel extensions of metaphor. This is referred to as "metaphorical entailments", and an example could be referring to a relationship as "going backwards", which would only be used with a negative import. An entailment, then, is a predictable manipulation and extension of what is known about the source domain to shed light on various aspects of the target domain. The lower case, italicised examples are seen to be linguistic manifestations of underlying conceptual metaphors which are part of the human conceptual system, and an inextricable part of higher order cognitive functioning.

Kövecses (2010: 9-10) uses the following format to explain how metaphors are constructed, where the linguistic expression is mentioned first, followed by the conceptual metaphor, which is then illustrated as a table showing the mapping of the metaphor between two conceptual domains. With the current example, this can be illustrated as follows:

Table 1: Mapping for LOVE IS A JOURNEY

\begin{tabular}{|l|r|l|}
\hline Source: JOURNEY & & Target: LOVE \\
\hline Travellers & $\rightarrow$ & Lovers \\
\hline Vehicle & $\rightarrow$ & The relationship \\
\hline The journey & $\rightarrow$ & Events in the relationship \\
\hline Obstacles on the road/path & $\rightarrow$ & Difficulties in the relationship \\
\hline Distance covered & $\rightarrow$ & Progress made \\
\hline Reaching destination & $\rightarrow$ & Culmination of the relationship (marriage?) \\
\hline Decisions about which way to go & $\rightarrow$ & Choices about what to do \\
\hline
\end{tabular}

Source: Author's own work

CMT has evolved over the years, and Lakoff (2014) summarises the various stages that the theory has been through. For the purpose of this study, the standard theory is used, as the nuances of the different versions over the years are not quite relevant, and will distract from the crux of this study - interested readers are referred to the source just cited for a more in-depth theoretical outline.

A note regarding jargon in this study: the phrase "metaphorical idioms" seems unconventional, so it is necessary to clarify the use of such. Bergen (2012: 199) defines "idioms" as expressions with unique meanings, but adds that they "have metaphor built into them". Gibbs (1992) concurs, pointing out that idioms are largely motivated by conceptual metaphors, and scholars such as Bergen (2012: 199-200) make use of the phrase "metaphorical idioms", which the current study has adopted.

This article aims to make a two-fold contribution: first, to shed some light on a few common sayings in SAIE, and second, to demonstrate from a cognitive linguistic perspective that these idioms are actually based on well-entrenched conceptual metaphors, and are therefore not as idiosyncratic as one may think. 


\section{South African Indian English}

South African English as a whole is interesting for various reasons, given the unique multicultural and multi-racial make-up of South African society. The legacy of apartheid, with legislation like the Group Areas Act, precluded different race groups from living in the same areas. Hence, varieties of English developed more or less along racial lines.

The "standard" variety of English in South Africa has been defined by Barnes (1992: 146) as that variety spoken by White South Africans with " 1820 settler blood coursing through [their] veins". Since English was the lingua franca, the Black communities have developed their version of South African English, commonly referred to as "Black South African English". Likewise, Afrikaner Whites, Coloureds and Indians developed varieties of English unique to their respective communities, notwithstanding the fact that there are nuances within the communities as well. Work by Mesthrie $(2010 \mathrm{~b}, 2012)$ has demonstrated that this is obviously an over-simplification, and the post-apartheid drive for "upward social mobility" amongst previously disadvantaged persons clearly plays a role in language shift. Mesthrie (2010b) argues that Black South Africans are more likely to emulate the standard SAE variety with respect to the GOOSE ${ }^{6}$ vowel, though the details are beyond the scope of the current study, and are mentioned here simply to highlight the fact that these ethnolectal boundaries are not clear-cut. Whilst Mesthrie (2010b) discusses language shift across the various race groups, and concludes that this phenomenon is more salient with speakers of Black South African English, Mesthrie (2017) argues along these lines with specific reference to the Black community in South Africa.

In 1950, shortly after the National Party came into power under the leadership of Jan Smuts, the Group Areas Act was introduced. When it became law, it was actually the title of three separate acts which prevented different race groups from associating. People who were not White, who had no option but to pass through the "white" areas, usually for work, were forced to carry pass books, and failure to do so led to arrest. According to Lass (1995: 89), English has "diffused from white European (specifically British) mother-tongue speakers to other communities", due simply to the expedient need for communication amongst the various groups (Lass 1995: 89).

One interesting consequence of this is that the various racial groups, due to being segregated, developed distinct varieties. For this reason, "White", "Coloured" and Indian English in South Africa are still distinct, though there are obviously nuances within the various varieties. Of course, since 1994, a lot has changed in South Africa. Mesthrie (2012: 372) discusses the contention with these racial categories, pointing out "that classifications of people characteristic of the now defunct apartheid era should not be used uncritically" because these are "complex and fluid" concepts. Mesthrie (2012: 374) later adds that the four official racial labels are indeed complex because "they conceal a constant state of flux", followed by a discussion as to how even within the Indian community, the label is more problematic than it seems. The author would like to add, in addition to Mesthrie's discussion on the role of religion, that current-day Pakistan was at the time of indenture (from 1860-1911) part of India, and some immigrants at the time may have been Muslims of Indian descent, which is no longer the case. Furthermore, such persons may not want to now self-identify as "persons of Pakistani descent", and may want to dispense with the label altogether. Nevertheless, the nuances and complexities in this regard require a study in itself, and is therefore beyond the scope of the current article. What is

\footnotetext{
${ }^{6}$ Glossed as in the original; the upper case here does not imply a hypothetical conceptual domain as the cited study was not within the framework of Cognitive Semantics.
} 
of more relevance here is that, like the informants in Mesthrie's (2012: 375) study, none demonstrated any discomfort with the label "Indian".

With regard to SAIE, Naicker (2012: 118) says the following:

SAIE is distinguished from other dialects of English in two ways: firstly, the Indian community in South Africa speak a variety of English with native speaker proficiency, hence, it is a misnomer to deem the said variety as a 'dialect'; secondly, given the relative geographic isolation of Indians historically, this variety, though it has become the L1 for most speakers of the variety, is still linguistically unique and imbued with rich cultural, social and religious idiosyncrasies, which is unusual in a South African set-up.

It is therefore interesting that the current generation of South African Indians are by and large monolingual speakers of English, although it is not true that dialectal variety and speaking the language as an L1 are mutually exclusive, hence the adoption of Trudgill's more neutral term "variety" in this article - this marks a shift in the use of the term from Naicker (2012). Furthermore, given the pressures to assimilate into current South African society, there is concomitant language shift taking place, with "an ever-changing range of basilect, mesolect and acrolect, which Mesthrie has documented quite extensively in some of his previous work" (Naicker 2012: 118).

Mesthrie is one of the few linguists who has looked at the variety of SAIE in a serious, scholastic context, and has published both books and articles on various aspects of SAIE from diachronic and synchronic perspectives. The current study aims to zoom in on a particular aspect of the variety, and analyse it from a Cognitive Linguistic perspective with reference to particular idioms in light of CMT.

Before going into the actual analysis, the method used to gather the data will be briefly outlined in the following section.

\section{Method}

Based on data from Mesthrie (1992: 85-89), which has a separate section on expressions unique to SAIE, expressions which were clearly idiomatic in nature were selected and discussed with a group of 10 monolingual, native speakers of SAIE. Expressions which were not fixed idioms, but were listed as idiosyncrasies of SAIE, were not included, which also precluded the list of slang terms used primarily by the youth (Mesthrie 1992: 105-120). The reason for this is simply due to the fact that this study aims to focus specifically on metaphorical idioms.

After the various idioms were shown to the participants, they were asked to choose some of the most intuitively salient or recognisable sayings, and were then asked to explain what the import of those idioms were, with reference to various real-life examples. This, together with the definitions or explanations provided in Mesthrie (1992), and the author's own native-speaker intuition, was taken as a fairly accurate explanation as to the import of these various metaphorical idioms. 
For ease of reference, the first metaphorical idiom will be referred to as "MI1", the second metaphorical idiom referred to as "MI2", and so on. The meaning put forth here is taken from the same source as the idiom itself, though not necessarily verbatim.

What follows is an analysis of the various idioms chosen. As previously mentioned, the presentation of the data is based on Kövecses (2010: 9-10), though it is slightly adapted here since Kövecses did not use idioms in his analysis. First, the metaphorical idiom is presented, seen as a linguistic manifestation of an underlying conceptual metaphor, much like a linguistic metaphor. Then the meaning is presented, cited verbatim from the source text. Thereafter, the hypothetical conceptual metaphor upon which the metaphorical idiom is based is presented, followed by an illustration of the mapping in table form. Finally, a brief discussion of the import of the MI is presented.

\section{Analysis}

\subsection{Metaphorical Idiom 1}

Metaphorical Idiom (MI) 1: Not fit (Mesthrie 1992b: 85)

Meaning: 'Fit not nothing, hopeless, no good'

Conceptual metaphor: GENERAL ABILITY/SKILL IS PHYSICAL FITNESS

Table 2: Mapping for GENERAL ABILITY/SKILL IS PHYSICAL FITNESS

\begin{tabular}{|l|l|c|}
\hline \multicolumn{1}{|c|}{ Source: PHYSICAL FITNESS } & & Target: GENERAL ABILITY/SKILL \\
\hline $\begin{array}{l}\text { Physical stamina } \\
\text { Motor skills } \\
\begin{array}{l}\text { Hand-eye coordination } \\
\text { Kinaesthetic ability }\end{array}\end{array}$ & $\rightarrow$ & Ability to carry out a task properly \\
\hline
\end{tabular}

\subsubsection{Import of MI1}

It is interesting that Mesthrie sometimes uses colloquialisms to explain the meaning(s) of the expressions in the cited work, often resulting in a circular definition, as in the current example where not fit is explained as "fit for nothing". However, the latter phrase has been more widely used than the former, so there is arguably no categorical redundancy. As an aside, in his review of A Dictionary of South African Indian English, Naicker (2012) did point this out, though it was very much a peripheral issue. The point is that the meaning is clear, as this refers to cases where someone is unable to do something s/he should be reasonably expected to do, and consistently fails to do so. Hence, this MI is almost always used pejoratively. It can also be used to relate to very abstract skills from running a household effectively, to being a good spouse - one informant when complaining about her husband's lack of interest in her says, "What kind husband he is not fit for anything!". This was a general reference to often forgetting to purchase certain items from the shop, not supporting her in matters pertaining to the disciplining of the children, etc. This could be seen as an instantiation of an underlying conceptual metaphor which is indeed present in standard English, but which plays out linguistically slightly differently, as when one says that "one needs stamina to read Tolstoy" (due to the length and concomitant mental attention/focus needed to get through one of his novels), and even plays out in labelling certain phenomena pertaining to attention in general, as in the case with "decision fatigue" (cf. Anderson 
2003). These are clearly metaphorical uses of the concepts 'stamina' and 'fatigue', as these do not relate to physical but mental skills.

\subsection{Metaphorical Idiom 2}

Metaphorical Idiom 2: Catch up (Mesthrie 1992b: 85)

Meaning: 'To catch on, comprehend'

Conceptual metaphor: COMPREHENSION IS GRASPING

Table 3: Mapping for COMPREHENSION IS GRASPING

\begin{tabular}{|c|c|c|}
\hline Source: GRASPING & & Target: COMPREHENDING \\
\hline Grasping an object & $\rightarrow$ & Understanding a concept \\
\hline Inability to grasp an object & $\rightarrow$ & Inability to understand something \\
\hline Holding on to an object & $\rightarrow$ & Having a concept ready for analysis/critique \\
\hline
\end{tabular}

\subsubsection{Import of MI2}

This MI is often used when engaged in lively conversation, and when one of the interlocutors seems to miss an innuendo, joke or reference. Having to explain the MI ex post facto often carries a social stigma with it, and is a bit of an indictment as it shows that the "accused" is either somewhat obtuse or not part of that in-group. During one conversation, a speaker mentioned that he referred to a scenario in the home as "becoming another Inanda", which was an obscure reference to someone in the family who lived in this area, and allegedly had an extra-marital affair some years ago. Upon missing this reference, one of the interlocutors was told to "catch up". Once an object is grasped, it can be manipulated and examined in various ways, just as a reference or concept can be expounded upon with all its entailments once it has been understood. The underlying conceptual metaphor has several variations in the literature, and a variety of entailments, including the metaphors UNDERSTANDING IS GRASPING (Gibbs 2011: 537) with the entailment that INABILITY TO UNDERSTAND IS INABILITY TO GRASP, as well as THINKING IS OBJECT MANIPULATION and IDEAS ARE OBJECTS, all of which have been discussed extensively in the literature pertaining to CMT (cf. Lakoff and Johnson 1980, 1999). MI2 could also be seen as a variant of the well-known English sayings "catch a wake up" and "get with the programme". It is interesting to note that an online dictionary defines the more conventional idiom "catch on" as "to grasp something mentally"7 (italics added), which lends credence to the idea that this is also based on the same underlying conceptual metaphor, although these are used in slightly different contexts; the mixing of metaphors here is a point to note.

\subsection{Metaphorical Idiom 3}

Metaphorical Idiom 3: To come down (Mesthrie 1992b: 86)

Meaning: 'To fail an examination (euphemism)'

Conceptual metaphor: BETTER IS UP

\footnotetext{
${ }^{7}$ https://www.dictionary.com/browse/catch--on
} 
Table 4: Mapping for BETTER IS UP

\begin{tabular}{|c|c|c|}
\hline Source: UP & & Target: BETTER \\
\hline Being physically upright & $\rightarrow$ & Being academically successful \\
\hline Not being physically upright & $\rightarrow$ & Being academically unsuccessful \\
\hline
\end{tabular}

\subsubsection{Import of MI3}

Within the context of the South African Indian diaspora, works by Desai and Vahed (2010) and Dhupelia-Mesthrie (2000) illustrate the role education has played in allowing the people who were once indentured labourers to transcend the state of veritable slavery, and become citizens who held respectable jobs. In this light, education was seen as a priority, and subsequent generations were encouraged to study in vocationally-orientated fields or areas so as to be relevant to the workplace at the time. An informant claims that the reason most South African Indians are monolingual speakers of English (though indeed most are multi-lectal, this sadly seems to matter only to the sociolinguist!) is to fit in not only to the British educational system, but also to the South African workplace. It is for this reason that failure to succeed in a formal educational system carries with it a serious stigma, to the point where a euphemism like the one under discussion has evolved - simply referring to "failure" in an examination is anathema, and brings shame upon the family. It is spoken about in whispers, and only when coerced is it referred to euphemistically as "coming down". One informant speaks of a nephew who did very well in school, and now has a very good job, but who "came down in one subject in matric". Though this might seem like a lexeme which refers to a very specific situation, it is interesting to note that there are other metaphorical idioms documented by Mesthrie which seem to be clear instantiations of the same BETTER IS UP conceptual metaphor. These are "to tension someone up" (Mesthrie 1992b: 88 - cited as in original), meaning "to discipline, scold severely, arraign, set right [probably based on the military idiom "tension up"]", and "to jack someone up", meaning "scold [from device for lifting heavy objects]" (Mesthrie 2010a: 108 - cited as in original). With the former, the mapping pertains to discipline and obedience, but is generally seen in a positive light within a military frame; with the latter, one could map this with a broken vehicle as a source domain which needs to be fixed, starting with a jack - just as a person's deviant behaviour needs to be fixed, starting with a scolding and acknowledgement before the actual infringement is fixed, so does a vehicle need to be jacked up first before the tyre is changed, for example. This orientational metaphor has been discussed by various scholars to pertain to various general situations, starting with a discussion by Lakoff and Johnson (1980: 15-18), who discuss various examples, like "feeling down" as feeling sad or sick, and being in "high spirits" as being positive, and so on.

\subsection{Metaphorical Idiom 4}

Metaphorical Idiom 4: To give it a go (Mesthrie 1992b: 86)

Meaning: 'To have a go at something; to enjoy doing something'

Conceptual metaphor: LIFE IS MOVEMENT

Table 5: Mapping for LIFE IS MOVEMENT

\begin{tabular}{|c|c|c|}
\hline Source: MOVING & & Target: ACHIEVEMENT \\
\hline Moving & $\rightarrow$ & Attempting a task \\
\hline
\end{tabular}




\subsubsection{Import of MI4}

This is typically used to refer to people who are hesitant to try something, sometimes because it is new, but often just because it is a subtle dare. This would typically relate to a task where someone is challenged to try doing something like rock climbing or bungee jumping, which is outside the repertoire of his/her normal routine. One informant speaks of a cousin who wanted to ride a motorbike, and was afraid; he was told to "give it a go", otherwise he would "never know". A related expression is "to give someone a go" (Mesthrie 1992b: 86), which means to challenge another person at something; this could also refer to sports teams, where one can say that South Africa gave Australia a go when referring to a cricket match. Although Mesthrie (1992b: 86) says that this saying implies victory, almost all informants agree that it simply denotes a situation where a challenge is presented, without necessarily predicting the outcome - though the connotation is that it was a "close call", meaning that the opponent struggled to achieve victory but eventually did. It should be noted that the informants in this study belong to the "upwardly mobile" set of Indians who are educated, and are therefore prone to being influenced by mainstream pop culture, and thus mainstream "standard" English, including SAE - this could be why their interpretations differed slightly from that of Mesthrie's. Lakoff (1993: 240) discusses the DIFFICULTIES ARE IMPEDIMENTS TO MOTION conceptual metaphor, which of course has the entailment that when there are no impediments, it would be easier to succeed in one's given task. There is the added entailment here that should one not choose to give it a go, then one is stagnant, and lacks ambition. Furthermore, this taps into the well-known LIFE IS A JOURNEY conceptual metaphor, where movement in general is a prerequisite but that forward movement is progress, and stagnation/backward movement is "death"/regress.

\subsection{Metaphorical Idiom 5}

Metaphorical Idiom 5: Where there's water, you must go drink (Mesthrie 1992b: 89)

Meaning: 'To take advantage of someone's weakness, generosity or promiscuity; to take advantage of a situation'

Conceptual metaphor: DESIRE IS THIRST

Table 6: Mapping for DESIRE IS THIRST

\begin{tabular}{|c|c|c|}
\hline Source: THIRST & & Target: DESIRE \\
\hline Thirst for something & $\rightarrow$ & Desire for something \\
\hline Water & $\rightarrow$ & That which fulfils the desire \\
\hline Act of drinking & $\rightarrow$ & Indulging in a sensual act \\
\hline
\end{tabular}

\subsubsection{Import of MI5}

This MI is used to refer to someone who is in a position of power, and has the option of whether or not to exploit the situation. Invariably, the reference to taking advantage of someone's promiscuity smacks ostensibly of misogyny, but in context is often used by men to explain away a physical encounter with a woman which he is embarrassed about amongst his peers. Of course, the MI can be used in other ways, like when taking advantage of an affluent donor in an organisation, or even when manipulating someone because of their generosity. The very same conceptual metaphor has been used to explain a variety of water-related metaphors in modernday Hindu and Chinese philosophical thought (cf. Naicker 2016 and Lu 2012), though it is evident 
from the discussion that, in line with Refaie (2003: 89), there is a "high context dependency" at play with this particular expression.

As an aside, water is a universal human need, and therefore it is unsurprising that this source domain has been used in other expressions in SAIE. When water boils, it is associated with some kind of intense activity, for example, so one informant said that when they went fishing, "the fish was [sic] boiling", meaning that there was an abundance of fish. The word "red" as a metonym for anger, as in "I was red for him" (meaning "I was angry with him"), could be seen as a result of increased levels of blood flow causing a red appearance in the face, much like the etymology of the idiom "hot under the collar". Littlemore (2009: 110-111) points out that it is "difficult to tease [metaphor and metonymy] apart" because a "great deal of metaphor actually starts life as metonymy". She specifically cites the example "hot under the collar", which would have initially been a literal association with anger, represented as ANGER FOR FEELING HOT UNDER THE COLLAR. Other idioms in SAIE, like "my blood was boiling" can also be related to human physiology, and Kövecses $(2008,2010)$ discusses quite extensively metaphors pertaining to anger as fluid boiling in a closed container.

\section{Conclusion}

The previous section discussed the imports of five salient metaphorical idioms used within the community of speakers of SAIE, based on Mesthrie (1992b, 2010a), and were cross-checked with members of the speech community who are native speakers. Aside from explaining how these metaphorical idioms are used, with reference to speakers' lived experiences, the author also argued that these idioms are actually based on well-entrenched conceptual metaphors which can form the basis for other "standardised" idioms. The following conceptual metaphors were put forth as the basis for the metaphorical idioms discussed:

\section{MI1: GENERAL ABILITY/SKILL IS PHYSICAL FITNESS \\ MI2: COMPREHENSION IS GRASPING \\ MI3: BETTER IS UP \\ MI4: LIFE IS MOVEMENT \\ MI5: DESIRE IS THIRST}

The point is that although these sayings are ostensibly idiosyncrasies of SAIE, they are based on what seem to be universal underlying conceptual metaphors which is why, for example (cf. MI5), the well-known English saying "you can take a horse to water, but you can't make it drink" would make sense, though it may be interpreted differently at the outset. The implication here is that these are simply variations of an underlying competence which is entrenched in all speakers of the same language.

Regarding recommendations for future study, this is a fertile field for future research, and it would be interesting to see whether all metaphorical idioms are actually based on established conceptual metaphors. Should there be exceptions, it could show that the general thesis of this study is flawed, or a case could be made that there are indeed some culturally unique conceptual metaphors, but that remains to be seen. Lastly, the etymologies of the idioms discussed here were not expanded upon since they were not mentioned in the source texts. When known, the author of the source texts did indeed speculate about the origins of the relevant words or phrases, but in the current study this was not discussed partly because it is a synchronic study. 
In this regard, a diachronic study which looks into the history of these idioms would be an interesting and insightful study, and can make for a fruitful research programme for future research - although Naicker (2019) argues that this mindset entails superimposing a Western purview when interpreting idioms from other linguistic and cultural groups. Once again, this is an interesting avenue for future research.

\section{References}

Anderson, C. 2003. The psychology of doing nothing: Forms of decision avoidance result from reason and emotion. Psychological Bulletin 129: 139-167. https://doi.org/10.1037/0033$\underline{2909.129 .1 .139}$

Barnes, L. 1992. Review of 'A Dictionary of South African English'. English Usage in Southern Africa 23: 145-149.

Bergen, B.K. 2012. Louder than words: The new science of how the mind makes meaning. New York: Basic Books.

Desai, A. and G. Vahed. 2010. Inside Indian indenture: A South African story, 1860-1914. Cape Town: HSRC Press.

Dhupelia-Mesthrie, U. 2000. From cane fields to freedom. Cape Town: Kwela Books.

Gibbs, R.W. 1992. What do idioms really mean? Journal of Memory and Language 31:485-506. https://doi.org/10.1016/0749-596x(92)90025-s

Gibbs, R.W. 2011. Evaluating conceptual metaphor theory. Discourse Processes 48: 529-562. https://doi.org/10.1080/0163853x.2011.606103

Kövecses, Z. 2008. Conceptual metaphor theory - Some criticisms and alternate proposals. Annual Review of Cognitive Linguistics 6(1):168-184. https://doi.org/10.1075/arcl.6.08kov

Kövecses, Z. 2010. Metaphor - A practical introduction. Oxford: Oxford University Press.

Lakoff, G. 1993. The contemporary theory of metaphor. In A. Ortony (Ed.) Metaphor and thought. Cambridge: Cambridge University Press. pp. 202-251.

https://doi.org/10.1017/cbo9781139173865.013

Lakoff, G. 2014. Mapping the brain's metaphor circuitry: Metaphorical thought in everyday reason. Frontiers in Human Neuroscience 8: 1-14. https://doi.org/10.3389/fnhum.2014.00958

Lakoff, G. and M. Johnson. 1980. Metaphors we live by. Chicago: University of Chicago Press.

Lakoff, G. and M. Johnson. 1999. Philosophy in the flesh: The embodied mind and its challenge to Western thought. New York: Basic Books. 
Lass, R. 1995. South African English. In R. Mesthrie (Ed.) Language and social history - Studies in South African sociolinguistics. Claremont: David Philip Publishers. pp. 89-106.

Littlemore, J. 2009. Applying cognitive linguistics to second language learning and teaching. Basingstoke: Palgrave Macmillan.

Lu, Y. 2012. Water metaphors in 'Dao de jing': A conceptual analysis. Open Journal of Modern Linguistics 2: 151-158. https://doi.org/10.4236/ojml.2012.24020

Mesthrie, R. 1991. Language in indenture: A sociolinguistic history of Bhojpuri-Hindi in South Africa. Johannesburg: Witwatersrand University Press. https://doi.org/10.4324/9780429434709

Mesthrie, R. 1992a. English in language shift: The history, structure and sociolinguistics of South African Indian English. Johannesburg: Witwatersrand University Press.

https://doi.org/10.1017/cbo9780511597893.012

Mesthrie, R. 1992b. A lexicon of South African Indian English. Leeds: Peepal Tree Press.

Mesthrie, R. 2010a. A dictionary of South African Indian English. Claremont: UCT Press.

Mesthrie, R. 2010b. Socio-phonetics and social change: Deracialisation of the GOOSE vowel in South African English. Journal of Sociolinguistics 14(1): 3-33. https://doi.org/10.1111/j.14679841.2009.00433.X

Mesthrie, R. 2012. Ethnicity, substrate and place: The dynamics of Coloured and Indian English in five South African cities in relation to the variable (t). Language Variation and Change 24: 371-395. https://doi.org/10.1017/s0954394512000178

Mesthrie, R. 2017. Class, gender, and substrate erasure in sociolinguistic change: A sociophonetic study of schwa in deracializing South African English. Language 93(2): 314-346. https://doi.org/10.1353/lan.2017.0016

Naicker, S. 2012. Review of 'A Dictionary of South African Indian English'. Language Matters 43(1): 117-123.

Naicker, S. 2016. Analysis of water-related metaphors within the theme of religious harmony in Swami Vivekananda's Complete Works. HTS Teologiese Studies/Theological Studies 72(4): 1-8. https://doi.org/10.4102/hts.v72i4.3431

Naicker, S. 2019. On the neo-Vedanta as reconceptualised by Vivekananda in his 'Complete Works': A cognitive linguistic analysis in light of conceptual metaphor theory. Literator 40(1): a1528. https://doi.org/10.4102/lit.v40i1.1528

Refaie, E.E. 2003. Understanding visual metaphor: The example of newspaper cartoons. Visual Communication 2(1): 75-95. https://doi.org/10.1177/1470357203002001755

Trudgill, P. 1999. Standard English: What it isn't. In T. Rex and R.J. Watts (Eds.) Standard English - The widening debate. London: Routledge. pp. 117-128. 